\title{
Analisa Traksi Untuk Kendaraan Truk Angkutan Barang Jalur Denpasar-Gilimanuk
}

\author{
IGAK. Chatur Adhi ${ }^{\star}$, AAIA Sri Komaladewi ${ }^{\star \star}$, IKetut Adi Atmika ${ }^{\star \star}$, IGAK.Suriadi** \\ * Jurusan Teknik Mesin , Universitas Mataram \\ **Jurusan Teknik Mesin , Universitas Udayana \\ Email : empatadhi@yahoo.com; tutadi2001@yahoo.com; komala.dewi@me.unud.ac.id;
}

\begin{abstract}
Road condition and plain all of the line traffic Denpasar-Gilimanuk have many slope upward. Beside of many slope upward declivity and long slope upward have many variation too. We must give many attention for that condition in design minimum power engine to vehicle truck, beside the other factors like wind velocity, kind of asphalt, curves, etc.

The purpose of this research to recite road condition (slope upward, wind velocity ,density) all of the line traffic Denpasar - Gilimanuk, and then will be count minimum traction need of vehicle truck that across that road.

From this research result obtained that the needed traction to overcome all resistance especially slope upward resistance are $6000 \mathrm{~N}$ and the estimate needed power about $220 \mathrm{hp}$ from characteristic power torsi.
\end{abstract}

Key words : traction, grade resitance, power-torqe, engine power

\section{PENDAHULUAN}

Salah satu performa yang penting adalah kemampuan kendaraan untuk melakukan percepatan, melawan hambatan angin, melawan hambatan rolling, melawan gaya tanjakan dan kemungkinan untuk menarik suatu beban (truk dengan muatan). Gaya yang timbul pada roda penggerak untuk melawan hambatan tersebut disebut dengan gaya dorong atau gaya traksi. Gaya traksi yang terjadi pada bidang kontak roda penggerak dan jalan dipengaruhi oleh banyak faktor diantaranya adalah : karakteristik torsi mesin, karakteristik coupling, ratio dan tingkat transmisi, ratio gardan, karakteristik propeller shaft, diameter efektif roda, karakteristik kontak roda dan jalan. Dari sekian banyak parameter yang mempengaruhi salah satu yang sangat besar pengaruhnya adalah karakteristik torsi mesin atau daya mesin (engine) minimum. Jalur lalu lintas DenpasarGilimanuk setiap harinya dilalui kendaraan yang cukup padat, baik kendaraan roda dua maupun roda empat, kendaraan pribadi maupun kendaraan angkutan umum, angkutan barang kendaraan dalam kota maupun antar kota. Untuk kendaraan angkutan barang antar kota dalam propinsi maupun antar propinsi banyak dilayani oleh truk-truk ukuran kecil, sedang maupun besar (roda 6). Kondisi jalan dan medan sepanjang jalur lalu lintas Denpasar-Gilimanuk termasuk jalur yang mempunyai tanjakan yang cukup banyak, baik dari arah Denpasar ke Gilimanuk maupun arah sebaliknya. Disamping jumlah tanjakan yang cukup banyak, kemiringan dan panjang tanjakan juga bervariasi. Kondisi jalan dengan tanjakan seperti ini harus menjadi perhatian yang serius dalam menentukan kelayakan suatu truk angkutan barang bisa beroperasi. Disamping kondisi jalan, hal yang sangat penting harus diperhatikan adalah beratnya muatan/barang yang diangkut, tentunya dipadukan dengan regulasi berat barang yang dapat diangkut untuk kondisi jalan yang dilalui. Faktor-faktor hambatan yang lainnya misalnya, kecepatan angin sepanjang jalur tersebut, jenis aspal jalan, belokan dan yang lainnya.

Dari uraian diatas maka permasalahan yang dikaji dalam makalah adalah bagaimana menghitung kebutuhan traksi minimum pada berbagai kondisi operasi kendaraan truk angkutan barang untuk melakukan akselerasi dan mengatasi hambatan-hambatan sepanjang jalur Denpasar-Gilimanuk, sehingga dari kebutuhan traksi minimum tersebut, ditentukan kebutuhan daya engine minimum. Memperhatikan hal tersebut, merancang atau menentukan daya mesin (engine) minimum kendaraan angkutan barang yang beroperasi sepanjang jalur ini adalah hal yang mutlak diperlukan. Dengan demikian kemampuan kendaraan untuk melakukan akselerasi, melalui tanjakan, melawan gaya angin, serta melawan rolling resistance dapat dihitung dari kebutuhan traksi minimum untuk mengatasi hambatanhambatan tersebut, kemudian dapat 
dirancang atau dianalisa kebutuhan daya mesin minimumnya.

\section{METODE}

Survey lapangan dilakukan untuk mengumpulkan data kondisi jalan, diantaranya besarnya sudut tanjakan jalan dan panjang tanjakan tersebut, jenis aspal jalan untuk menentukan hambatan rolling, kecepatan rata-rata dan arah angin, data kepadatan jalur, dan data spesifikasi kendaraan truk angkutan barang yang melayani jalur tersebut, juga data beratnya muatan yang diijinkan.

Selanjutnya dari data-data yang terkumpul dilakukan analisa dengan menggunakan sistem transmisi standar terhadap kebutuhan traksi pada kendaraan ketika melintasi kondisi jalan yang berbedabeda (sepanjang jalur tersebut) dan kondisi muatan yang berbeda pula, kemudian diplot grafik karakteristik traksinya. Setelah didapatkan karakteristik traksi itu, dirancang atau dihitung kebutuhan daya mesin (engine) minimumnya dengan membuat grafik karakteristik daya-torsi engine secara umum, baik motor bensin atau mesin diesel.

Karakteristik traksi pada kendaraan bermotor pada pokoknya meliputi kemampuan kendaraan untuk dipercepat, dan mengatasi hambatan-hambatan yang terjadi, diantaranya hambatan rolling, hambatan tanjakan, juga hambatan aerodinamis. Dari konsep gaya inertia, diturunkan persamaan traksi dan secara umum dituliskan (Sutantra, 2001) :

$$
F=R_{a}+R_{r}+R_{d}+R_{g}+\frac{W}{g} \cdot a \cdot(1)
$$

Untuk pemakaian pada kendaraan bermotor, karakteristik daya guna ideal dari sumber tenaga penggeraknya adalah dihasilkan tenaga yang konstan pada semua tingkat kecepatan. Dengan tersedianya tenaga yang konstan tersebut, pada kecepatan yang rendah akan tersedia torsi yang cukup besar, akan dipergunakan untuk menghasilkan traksi yang cukup pada roda untuk mempercepat kendaraan. Dengan bertambahnya kecepatan, torsi mesin akan menurun secara hiperbolis. Hal ini sesuai dengan kebutuhan traksi pada kendaraan, dimana pada kecepatan yang cukup tinggi, kebutuhan traksi tidak lagi besar (Sutantra, 2001). Grafik Karakteristik Daya-Torsi kendaraan secara umum untuk setiap kecepatan ditunjukkan pada gambar 1 .

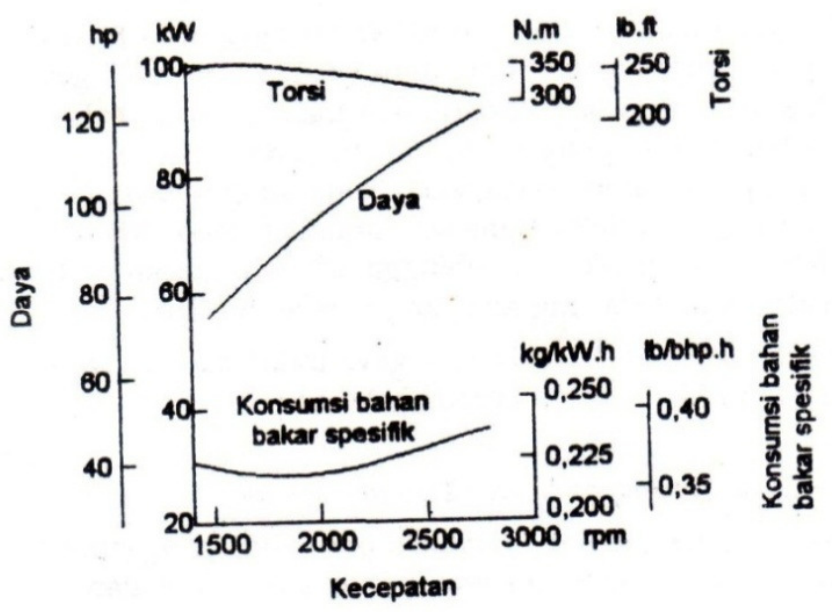

Gambar 1. Grafik Karakteristik Daya -Torsi kendaraan

Bila suatu sistem drive train
dikarakteristikkan parameter efisiensi sistem drive train $\left(\eta_{t}\right)$ dan perbandingan gigi reduksi (i), maka traksi pada roda penggerak dapat dirumuskan (Sutantra, 2001) :

$$
F_{k}=\frac{M_{e}(v) \cdot i_{k} \cdot i_{d}}{r} \eta_{t}
$$

Kemudian hubungan antara kecepatan kendaraan dan kecepatan putaran mesin (Sutantra, 2001) adalah :

$$
V=\frac{n_{e} \cdot r}{i_{d} \times i_{k}}(1-s)
$$

atau ditulis dalam satuan yang berbeda (Sutantra, 2001) : 


$$
V=\frac{0,06(1-s) \cdot \pi \cdot D \cdot N}{i_{d} \times i_{k}}
$$

Karakteristik beban angin yang ditunjukkan oleh koefisien aerodinamik mempunyai pengaruh terhadap stabilitas arah dan kemampuan traksi kendaraan (Hartana, 1993).

$$
F_{D}=\frac{1}{2} \cdot C_{D} \cdot \rho \cdot V_{a}^{2} \cdot A_{f}
$$

Hambatan tanjakan adalah salah satu hambatan yang harus bisa diatasi dalam merancang kebutuhan traksi kendaraan seperti dituliskan pada persamaan (1). Dengan demikian dibutuhkan data kondisi jalan yang menyangkut sudut tanjakan dan panjang tanjakan.
Modifikasi terhadap sistem transmisi baik sistem gear maupun gearless memberikan beberapa keuntungan dibandingkan dengan kendaraan pada kondisi standarnya, ditunjukkan dengan perbaikan kinerja traksi (Atmika, 2004)

\section{HASIL DAN PEMBAHASAN}

Berdasarkan beberapa model kendaraan truk yang ada, serta kajian kajian awal terhadap kinerja traksi, spesifikasi kendaraan model ditunjukkan pada table 1 . Kinerja traksi adalah sangat penting karena kendaraan truk angkutan barang yang akan dihasilkan harus mampu melalui berbagai kondisi/medan operasi sepanjang jalur Denpasar-Gilimanuk

\begin{tabular}{|c|c|c|c|c|}
\hline Data Kendaraan & & Notasi & Satuan & Besar \\
\hline & Massa total & $\mathrm{m}$ & $\mathrm{kg}$ & 4353 \\
\hline & Whell base & $\mathrm{L}$ & $\mathrm{m}$ & 3.830 \\
\hline & Beban Statis Poros depan & L1 & $\mathrm{m}$ & 2808 \\
\hline & Tinggi pusat massa & $\mathrm{h}$ & $\mathrm{m}$ & 0.850 \\
\hline & Track & $\operatorname{Tr}$ & $\mathrm{m}$ & 1.960 \\
\hline & Radius roda & $r$ & $\mathrm{~m}$ & 0.504 \\
\hline & Luas frontal kendaraan & $A_{f}$ & $\mathrm{~m}$ & 1.870 \\
\hline & $\begin{array}{l}\text { Mesin DIESEL dengan } \\
\text { torsi maksimum } 520 \mathrm{lb} \text {-ft } \\
\text { Nm pada } 1500 \mathrm{rpm}\end{array}$ & $\mathrm{Me}$ & $\mathrm{Nm}$ & 143 \\
\hline \multicolumn{5}{|l|}{ Transmisi } \\
\hline & Effisisnsi transmisi total & & & 0.900 \\
\hline & Ratio Transmisi & $i_{1}$ & & 9.808 \\
\hline & & $i_{2}$ & & 5.27 \\
\hline & & $\mathrm{i}_{3}$ & & 3.220 \\
\hline & & $i_{4}$ & & 2.040 \\
\hline & & is & & 1.361 \\
\hline & & $i_{6}$ & & 1.000 \\
\hline & Ratio gardan & $i_{s}$ & & 8.625 \\
\hline & tekanan ban depan & $\mathrm{p}: \mathrm{t}$ & $\mathrm{psi}$ & 26 \\
\hline & tekanan ban belakang & p. & $\mathrm{psi}$ & 30 \\
\hline
\end{tabular}

Tabel.1. Spesifikasi kendaraan model

Menggunakan pendekatan grafik pada gambar 1, karakteristik daya - torsi engine didapatkan grafik karakteristik daya-torsi engine kendaraan model seperti ditunjukkan pada gambar 2

\section{Perhitungan dan Analisa Kinerja Traksi}

Berdasarkan karakteristik daya-torsi engine (gambar 2) dihitung traksi kendaraan pada berbagi kecepatan (putaran mesin). Contohnya pada gigi I putaran mesin 2000 rpm.

- Kecepatan kendaraan ( V ) 


$$
\begin{array}{ll}
V=\frac{0,06(1-S) \pi D N}{i_{k} \cdot i_{d}} & V=15,07 \mathrm{~km} / \mathrm{jam}=4,17 \mathrm{~m} / \mathrm{s} \\
V=\frac{0,06(1-3 \%) \cdot 3,14 \cdot 0,60 \cdot 2000}{3,545 \cdot 4,105} & \cdot
\end{array}
$$

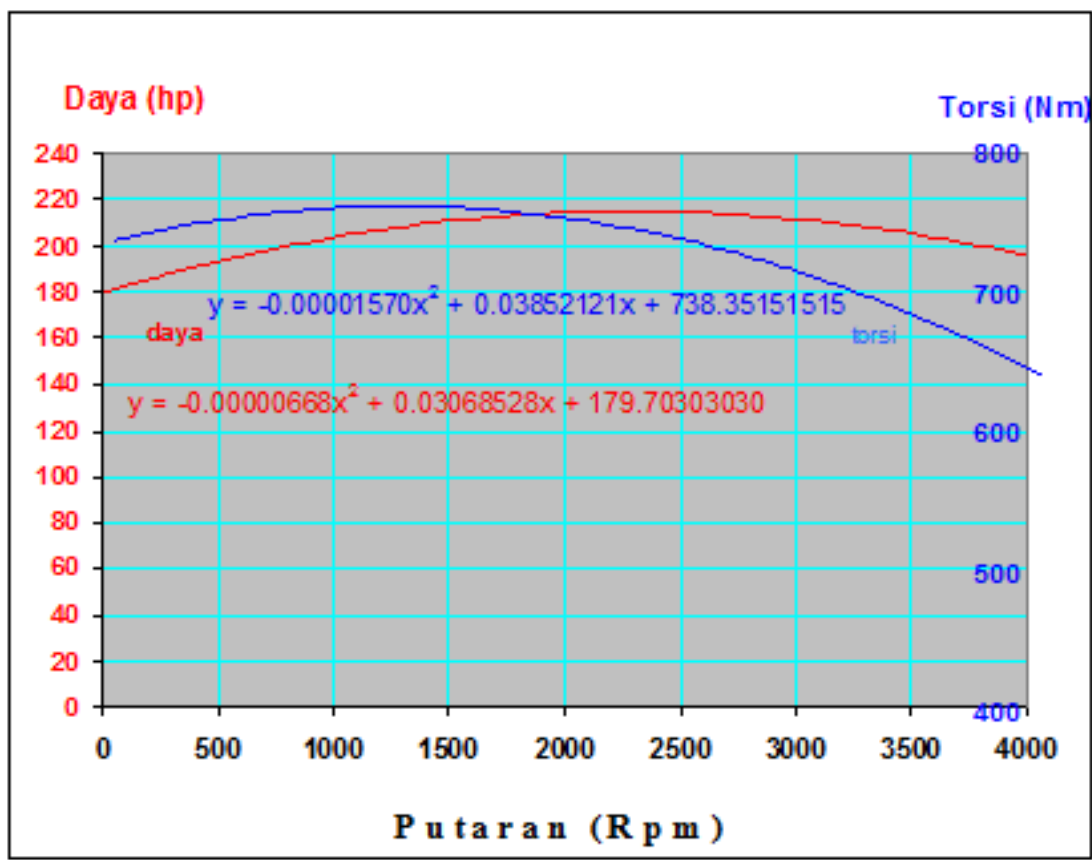

Gambar 2. Grafik karakteristik daya-torsi engine model

- Traksi total ( F )

$F=\frac{M_{e}(V) \cdot i_{k} \cdot i_{d}}{r} \cdot \eta_{t}$

$F=\frac{128,90 \cdot 3,545 \cdot 4,105}{0,3} .0,9$

$F=5627,45 N$

- Koefisien rolling resistance $\left(f_{r}\right)$

$f_{r}=f_{o}+f_{s}\left(\frac{V}{100}\right)^{2,5}$

$f_{r}=0,01+0,005\left(\frac{15,07}{100}\right)^{2,5}$

$f_{r}=0,038$

- Gaya angkat aerodinamis ( $\left.F_{L}\right)$

$F_{L}=\frac{1}{2} \cdot C_{l} \cdot \rho \cdot V_{a}^{2} \cdot A_{f}$

$F_{L}=\frac{1}{2} \cdot 0,15 \cdot 1,225 \cdot(4,19-5)^{2} \cdot 1,770$

$F_{L}=0,1073 N$

- Gaya hambat aerodinamis $\left(R_{a}\right)$

$$
\begin{aligned}
& R_{a}=\frac{1}{2} \cdot C_{d} \cdot \rho \cdot V_{a}^{2} \cdot A_{f} \\
& R_{a}=\frac{1}{2} \cdot 0,35 \cdot 1,225 \cdot(4,19-5)^{2} \cdot 1,770 \\
& R_{a}=0,2504 N
\end{aligned}
$$

- Rolling resistance $\left(\mathrm{R}_{\mathrm{r}}\right)$

$R_{r}=f_{r} .\left(W-F_{L}\right)$

$R_{r}=0,038 .(11270-0,1073)$

$R_{r}=482,256$

- Traksi bersih $\left(F_{\text {net }}\right)$

$F_{n e t}=F-\left(R_{a}+R_{r}\right)$

$F_{n e t}=5627,45-(0,2504+482,256)$

$F_{\text {net }}=5198,94 \mathrm{~N}$

- Percepatan yang dihasilkan ( a )

$a=\frac{F_{n e t}}{m}$

$a=\frac{5198,94}{1150}$ 


$$
a=4,521
$$

Hasil perhitungan selengkapnya disajikandalam bentuk grafik kinerja traksi untuk kendaraan uji pada kondisi kosong ditunjukkan dengan grafik kecepatan vs gaya dorong (traksi) pada gambar 3, gambar 4,

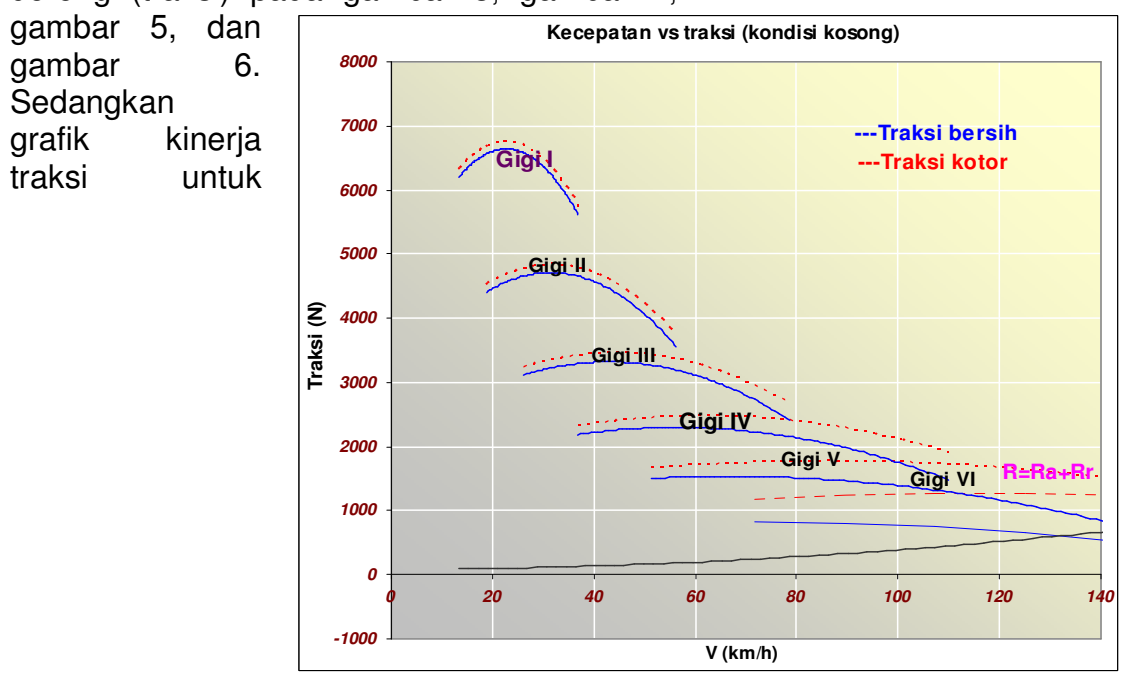

Gambar 3. Grafik karakteristik kinerja traksi kendaraan model pada kondisi kosong

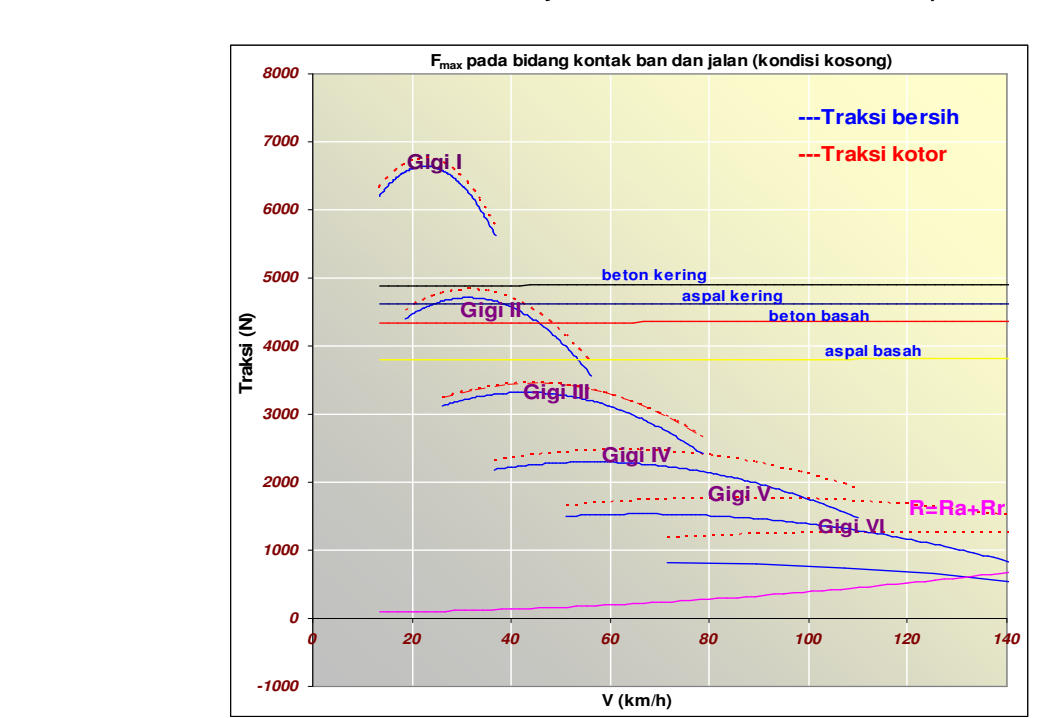

Gambar 4. Fmax untuk berbagai kondisi jalan pada kondisi kendaraan kosong kendaraan uji pada kondisi muatan/terisi penuh ditunjukkan dengan grafik kecepatan vs gaya dorong (traksi) pada gambar 7 , gambar 8, gambar 9, dan gambar 10. 


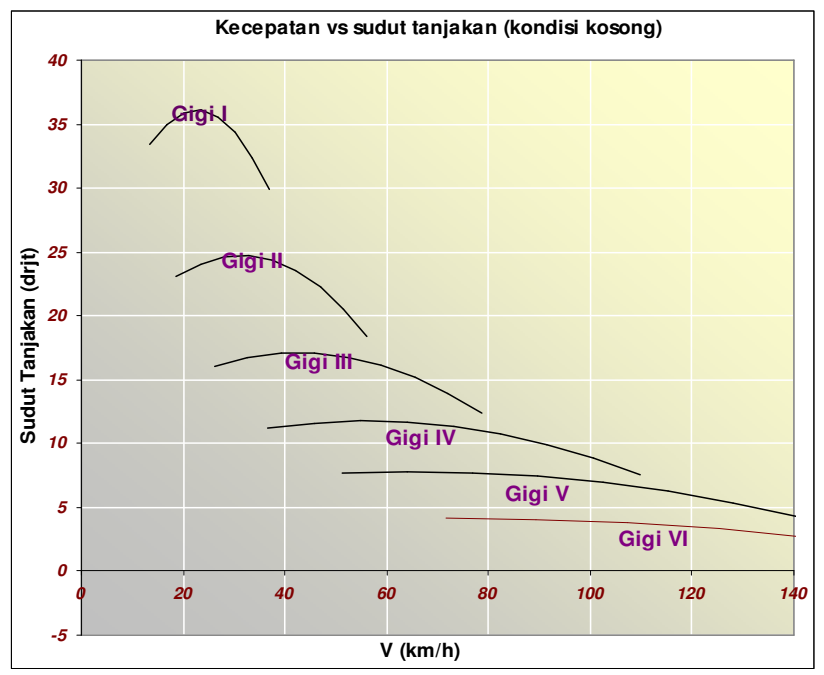

Gambar 5. Tanjakan yang mampu dilalui pada kondisi kendaraan kosong

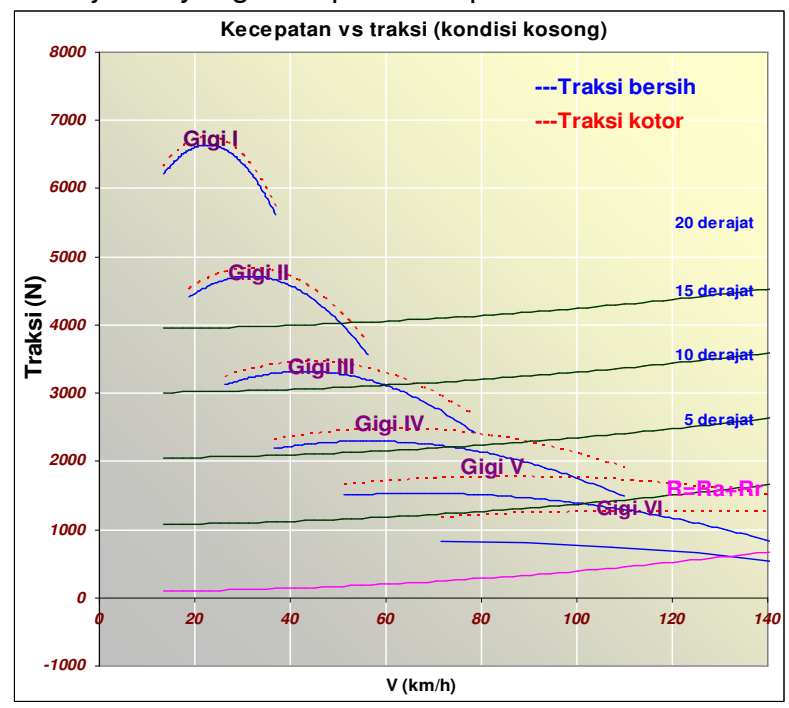

Gambar 6. Tanjakan yang mampu dilalui pada kondisi kendaraan kosong

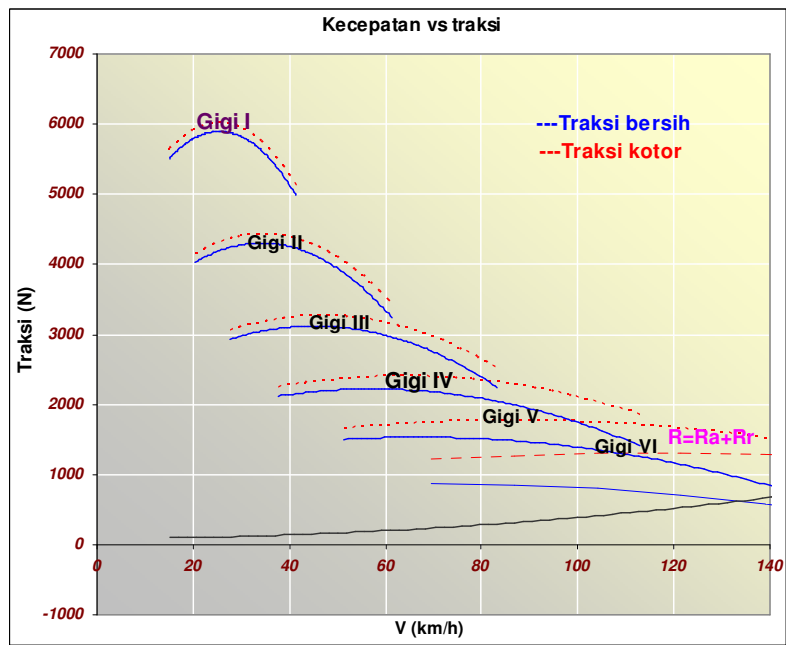

Gambar 7. Grafik Karakteristik Kinerja Traksi Kendaraan Model pada kondisi penuh 


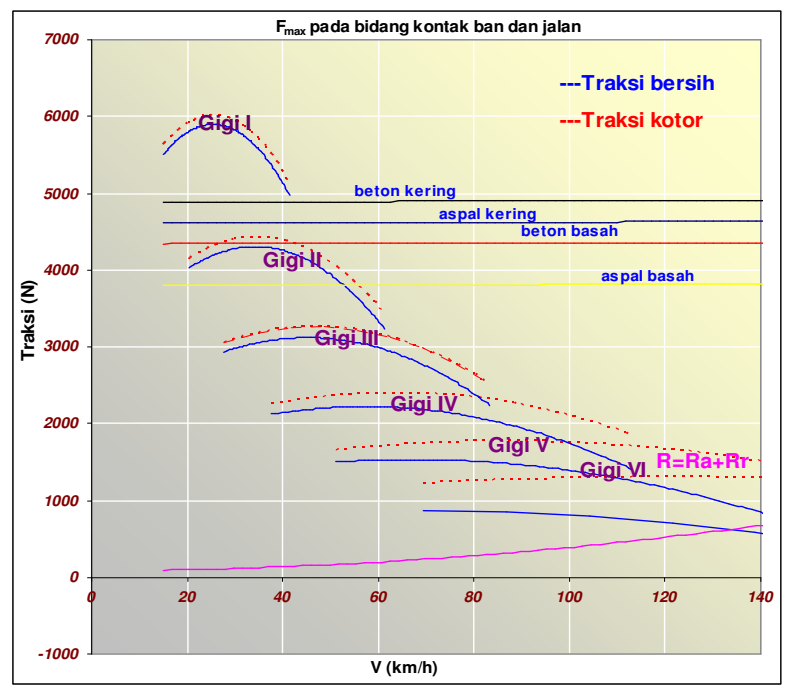

Gambar 8. Fmax untuk berbagai kondisi jalan pada kondisi kendaraan penuh

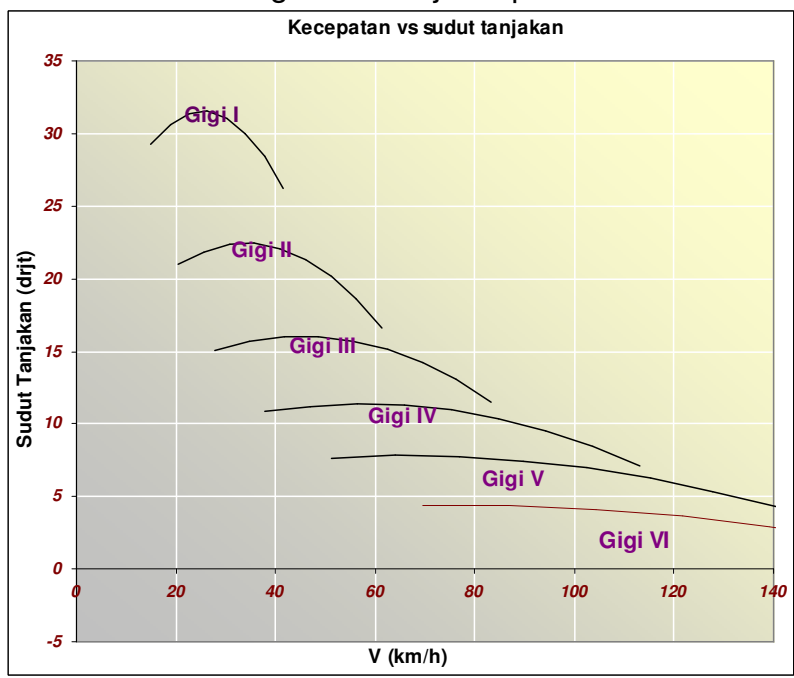

Gambar 9. Tanjakan yang mampu dilalui pada kondisi kendaraan penuh 


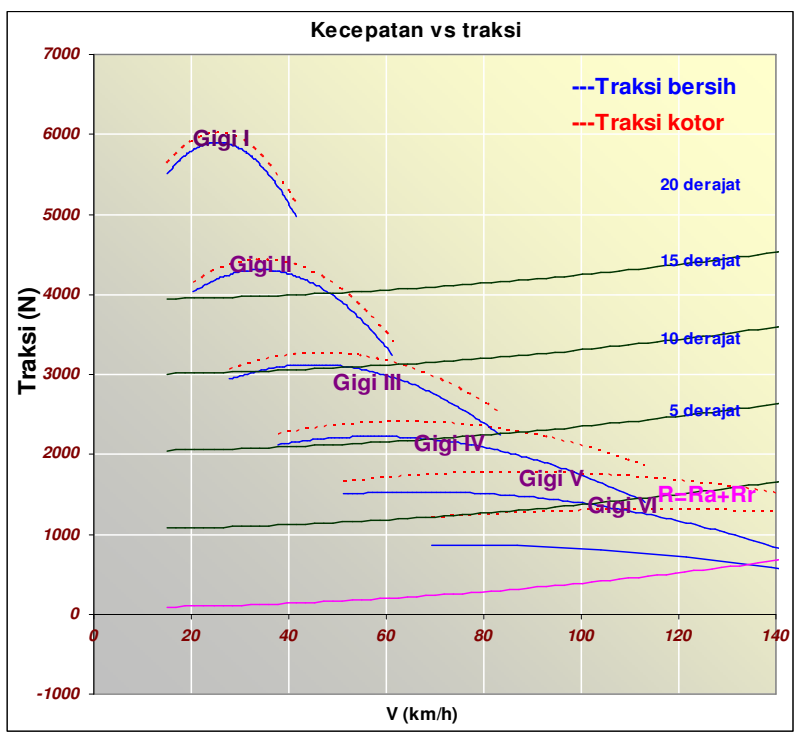

Gambar 10. Tanjakan yang mampu dilalui pada kondisi kendaraan penuh

Nampak kinerja traksi kendaraan model pada kondisi penuh mampu melalui berbagai kondisi jalan, dengan tanjakan yang mampu dilalui sampai 32 derajat.

Dari grafik kinerja traksi (gambar $3 \mathrm{~s} / \mathrm{d}$ gambar 10), gambaran traksi yang dibutuhkan untuk mengatasi segala hambatan khususnya hambatan tanjakan mencapai $6000 \mathrm{~N}$, kemudian dari karakteristik daya-torsi diperkirakan kebutuhan daya minimum sekitar $220 \mathrm{hp}$.

\section{KESIMPULAN}

Dari uraian dan analisa dapat disimpulkan bahwa karakteristik traksi yang dibutuhkan kendaraan truk angkutan barang untuk mengatasi segala hambatan sepanjang jalur Denpasar-Gilimanuk mencapai $6000 \mathrm{~N}$. sedangkan dari karakteristik daya-torsi, diprediksikan kebutuhan daya engine minimum mencapai $220 \mathrm{hp}$, dimana paling besar diperlukan untuk mengatasi hambatan tanjakan.

\section{Daftar Pustaka}

Agus Sigit P., Sutantra, Nyoman, Fauzan Iwan, Design and Performance of
Gearless Variable Transmission Applied for Automotive, Proc.FISITA, Soul, 2001.

Atmika, Adi, Karakteristik Traksi dan Kinerja Transmisi Pada Sistem Gear Transmission dan Gearless Transmission, Majalah IImiah Teknologi Elektro, Vol. 3 Nomor 2, Denpasar, 2004.

Hartana, Pande, Karakteristik Beban Angin dan Pengaruhnya Terhadap Perilaku Arah dan Kinerja Traksi Kendaraan, Teknik Mesin FTI - ITS Surabaya, 1993.

Sutantra, Nyoman, Teknologi Otomatif, Teori dan Aplikasinya, Penerbit Guna Widya, Edisi Pertama, Surabaya , 2001

Sutantra, Nyoman, Joni, Made, The Effect of Wind Forces on Vehicle Directional Stability, IPC-II on Automotive Eng., Bali, 1997.

Wong J.Y, Theory of Ground Vehicles, Jhon Wiley \& Sons Inc. 